\title{
Effect of Washing and Subsequent Heat Treatment on Surface Characteristic of Glass Fabric Treated with Fluorocarbon Resin
}

\author{
Muncheul Lee ${ }^{* 1}$, Kenji Nishi ${ }^{* 2}$,Masahiro Miyazaki ${ }^{* 2}$,Myung Sun Lee ${ }^{* 1}$, \\ Takako Tokuyama*3, and Tomiji Wakida*3 \\ ${ }^{* 1}$ Department of Textile Engineering, Pusan National University, Pusan 609-735, Korea \\ ${ }^{* 2}$ Meisei Chemical Works, Nishikyogoku, Ukyoku, Kyoto 615-8666, Japan \\ ${ }^{* 3}$ Department of Home Economics, Gifu Women's University, Taromaru, Gifu 501-2592, Japan
}

\begin{abstract}
It is well known that water repellency of the fabric finished with perfluorocarbon resin lowers by washing and recovers by subsequent heat treatment. Detail of the behavior of the water repellency is not always clear at present. In this article, glass fiber fabric which consists of a three dimensional silicate component was treated with commercial fluorocarbon resins, Asahi Guard AG-7000 and AG-925 (copolymer of fluoroalkyl acrylate and alkyl acrylate). Then, the fabric was washed and subsequently heat treated varying the temperature. After the processing, the water and oil repellencies were evaluated. The water and oil repellencies decreased by the washing and recovered by following heat treatment. ESCA measurement was carried out to investigate the surface chemical composition of the treated fiber. The $\mathrm{F}_{1 \mathrm{~s}}$ intensity of the treated fabric decreased by the washing and recovered by the subsequent heat treatment. On the other hand, the $\mathrm{O}_{\mathrm{Is}}$ intensity increased by the washing and decreased by following heat treatment. From the results, it is clear that change of the water and oil repellencies of the glass fabric treated with fluorocarbon resin causes by the washing and subsequent heat treatment. We considered that these behaviors of the treated fabric attributed greatly to the water bonded or clustered on the fabric surface during the washing and following heat treatment.
\end{abstract}

(Received 22 October, 2004 ; Accepted 26 August, 2005)

\section{Introduction}

Surface of the textile fiber plays an important role for the fabric characteristics such as the water and oil repellency, soil resistance, fabric hand and luster. Water repellency is one of the most practical textile property, and also it has been pointed out that the water repellency of the textile fabric treated with fluorocarbon resin decreased by the washing and recovered by the subsequent heat treatment [1]. The effect has been explained by the following consideration; i) rotation of the fluoroalkyl group of the fluorocarbon resin from surface to inside of the fiber by the washing to adapt to the hydrophilic circumstance, ii) deposition of the water which bonded or clustered on the fiber surface by the washing and release of the water by subsequent heat treatment, iii) disturbance of orientation of the fluoroalkyl groups of the resin by washing and recovery after the heat treatment. Above explanation is all speculation. Detail of the phenomenon is not clear at present [1-9].

In this experiment, glass fiber fabric was treated with two commercial fluorocarbon resins for the textile finishing (Asahi Guard AG-7000 and AG-925). Because the glass fiber has rigid and compact structure compared with other organic fiber, it is apparently difficult to transfer the fluoroalkyl group of the resin from surface into the glass fiber by the washing. Therefore, we are considering that a decrease of the water repellency of the resin treated fabric by washing can be explained as the surface phenomena of the resin layer on the treated fiber [4].

The resin treated fabrics were washed and heattreated varying the temperature. The water and oil repellencies were evaluated with JIS L 1092 and AATCC -118 methods after the processings. Furthermore, in order to investigate the surface characteristic of the treated fabric, ESCA analysis was carried out. Change of the $\mathrm{F}_{1 \mathrm{~s}}$, $\mathrm{O}_{1 \mathrm{~s}}$ and other chemical components during the processing were measured in relation to a parameter of the water and oil repellencies of the treated fabric.

\section{Experimental}

As a material, gray glass fabric produced by Unitika 
Glass Fiber Fabric Co. (plain fabric, thickness $0.17 \mathrm{~mm}$, weight $210 \mathrm{~g} / \mathrm{m}^{2}$ ) was used. Desizing and scouring were done by the same way as that of the textile fabric with Ractogen LS (Rakuto Kasei Ind. Co., Ltd.) and caustic soda. After the processing, the fabric was treated with two commercial fluorocarbon resins, Asahi Guard AG-7000 and AG-925 which are copolymer of fluoroalkyl acrylate and alkyl acrylate (Asahi Glass Co.) by the pad / dry $\left(110^{\circ} \mathrm{C} / 3 \mathrm{~min}\right) /$ cure $\left(160^{\circ} \mathrm{C} / 2 \mathrm{~min}\right)$ processing. The treated fabrics were washed by the JIS L 0217-103 method, dried $\left(110^{\circ} \mathrm{C} / 3 \mathrm{~min}\right)$, and subsequently heat treated $\left(50^{\circ} \mathrm{C} / 3 \mathrm{~min}, 80^{\circ} \mathrm{C} / 3 \mathrm{~min}\right.$ and $\left.120^{\circ} \mathrm{C} / 3 \mathrm{~min}\right)$. The water and oil repellencies were evaluated by the JIS L 1092 and AATCC-118 methods.

Water repellency by spray method was done according to following method, $250 \mathrm{~mL}$ water sprayed onto fabric fitted on a $20 \mathrm{~cm}$ diameter circular frame rotating in a plane at $45^{\circ}$ to the horizontal. The effect was evaluated with a pattern of the index between 1 and 5 , where 1 represents complete wetting out and 5 total water repellency.

Oil repellency test was carried out using the liquids shown in Table 1 approximately on the basis of the AATCC-118 method [10]. Beginning with the lowestnumbered test liquid, carefully place small drop (ca 0.05 $\mathrm{mL}$ ) on the test fabric. If no penetration or wetting of the liquid-fabric interface, place of the next higher-numbered test liquid. Observe the drop for $30 \pm 2$ seconds. Wetting of the fabric is normally evidenced by a darkening of the fabric at the liquid-fabric interface or by loss of sparkle within the drop. The oil repellency was obtained with the rating between 0 and 8 of the liquid which takes place the wetting.

To investigate the surface chemical composition, ESCA analysis was carried out with a VG Scientific ESCALAB 250 spectrometer, England. The relative intensity of the $\mathrm{C}_{1 \mathrm{~s}}, \mathrm{~F}_{1 \mathrm{~s}}, \mathrm{O}_{1 \mathrm{~s}}, \mathrm{Si}_{2 \mathrm{p}}$ and $\mathrm{Ca}_{2 \mathrm{p}}$ were determined with regard to the water and oil repellency of the glass fabric treated with fluorocarbon resin.

\section{Results and discussion}

\subsection{Water repellency}

Table 2 shows the water repellency of the fabrics treated with AG-7000 and AG-925. Untreated glass fabric is considerably wettable because of the chemical composition of the silicate which contain many oxygen atom in the material. Although the water repellency was improved remarkably by the treatment with AG-7000 and AG-925, the effect decreased apparently by the washing
Table 1 Liquids for oil repellency test by AATCC-118 method.

\begin{tabular}{lcc}
\hline Liquid & $\begin{array}{c}\text { Surface } \\
\text { tension } \\
\left(\mathrm{N} / \mathrm{m} \mathrm{x} 10^{3}\right)\end{array}$ & $\begin{array}{c}\text { Rating of } \\
\text { oil } \\
\text { repellency }\end{array}$ \\
\hline$n$-Heptane & 20.0 & 8 \\
$n$-Octane & 21.7 & 7 \\
$n$-Decane & 23.9 & 6 \\
$n$-Dodecane & 25.4 & 5 \\
$n$-Tetradecane & 26.5 & 4 \\
$n$-Hexadecane & 27.7 & 3 \\
$n$-Hexadecane/Nujor, 35/65 & 29.5 & 2 \\
Nujor & 32.8 & 1 \\
Salada oil & 33.0 & 0 \\
\hline
\end{tabular}

* The oil repellency improves with an increase of the rating.

Table 2 Water repellency of glass fabric treated with AG-7000 and AG-925.

\begin{tabular}{lcc}
\hline Treatment & AG-7000 & AG-925 \\
\hline Untreated & $1^{-}$ & $1^{-}$ \\
Resin treated & 5 & 4 \\
Washed/dried & 4 & $4^{-}$ \\
Heat-treated & & \\
$50^{\circ} \mathrm{C} / 3 \mathrm{~min}$ & $4^{+}$ & 5 \\
$80^{\circ} \mathrm{C} / 3 \mathrm{~min}$ & $5^{-}$ & 5 \\
$120^{\circ} \mathrm{C} / 3 \mathrm{~min}$ & $5^{+}$ & $5^{+}$ \\
\hline
\end{tabular}

Table 3 Oil repellency of glass fabric treated with AG7000 and AG-925.

\begin{tabular}{lcc}
\hline Treatment & AG-7000 & AG-925 \\
\hline Untreated & 0 & 0 \\
Resin treated & 5 & 5 \\
Washed/dried & 1 & 0 \\
Heat-treated & & \\
$50^{\circ} \mathrm{C} / 3 \mathrm{~min}$ & 3.5 & 4.5 \\
$80^{\circ} \mathrm{C} / 3 \mathrm{~min}$ & 4.5 & 5 \\
$120^{\circ} \mathrm{C} / 3 \mathrm{~min}$ & 4.5 & 5 \\
\hline
\end{tabular}

and increased gradually by the subsequent heat treatment. We suppose that a little water molecules were bonded on the fabric surface by the washing and leads to a decrease of the water repellency, and the water was released from the surface by the heat treatment. As the result, water repellency was recovered.

In a previous paper, we treated polyester film and fabric with fluorocarbon resins, and contact angle and 
critical surface tension (cst) were obtained by a Zisman plot [4]. Contact angle obviously decreased by washing and recovered by subsequent heat treatment, especially at temperature over $80^{\circ} \mathrm{C}$. Also, we reported the same water repellency on the cotton and polyester fabrics treated with fluorocarbon resin $[4,5,9]$. Therefore, it seems that the behavior by the fluorocarbon resin treatment takes place independent of the fiber substrate. From the results, it seems that change of the water repellency treated with fluorocarbon resin correlates a little water taken on the resin surface during the washing and following heat treatment.

\subsection{Oil repellency}

In order to obtain a soil resistance, it is necessary to improve not only the water repellency but also the oil repellency. For that purpose, fluorocarbon resin has been used widely in the textile finishing. Table 3 shows the oil repellency of the glass fabrics treated with AG-7000 and AG-925. The effect of the treatment is almost the same as that of the water repellency. Although the oil repellency obtained by the treatment decreased greatly by the washing and recovered with an increase of the heat treatment, especially over $80^{\circ} \mathrm{C}$. It seems that effect of the washing and subsequent heat treatment on the oil

Table 4 Relative chemical composition of AG-7000 treated glass fabric by ESCA analysis.

\begin{tabular}{lcrrrc}
\hline \multirow{2}{*}{ Treatment } & \multicolumn{5}{c}{ Relative intensity (\%) } \\
\cline { 2 - 6 } & $\mathrm{C}_{1 \mathrm{~s}}$ & \multicolumn{1}{c}{$\mathrm{F}_{1 \mathrm{~s}}$} & \multicolumn{1}{c}{$\mathrm{O}_{1 \mathrm{~s}}$} & $\mathrm{Si}_{2 \mathrm{p}}$ & $\mathrm{Ca}_{2 \mathrm{p}}$ \\
\hline Untreated & 56.6 & - & 29.0 & 11.4 & 3.0 \\
Resin treated & 42.3 & 50.0 & 6.9 & 0.8 & - \\
Washed/dried & 44.1 & 36.9 & 17.8 & 1.2 & - \\
Heat-treated & & & & & \\
$50^{\circ} \mathrm{C} / 3 \mathrm{~min}$ & 45.3 & 38.3 & 12.4 & 3.2 & 0.8 \\
$80^{\circ} \mathrm{C} / 3 \mathrm{~min}$ & 44.9 & 39.8 & 11.7 & 3.0 & 0.6 \\
$120^{\circ} \mathrm{C} / 3 \mathrm{~min}$ & 43.1 & 45.0 & 9.3 & 1.3 & 0.7 \\
\hline
\end{tabular}

Table 5 Relative chemical composition of AG-925 treated glass fabric by ESCA analysis.

\begin{tabular}{lrrrrr}
\hline \multirow{2}{*}{ Treatment } & \multicolumn{5}{c}{ Relative intensity (\%) } \\
\cline { 2 - 6 } & $\mathrm{C}_{1 \mathrm{~s}}$ & \multicolumn{1}{c}{$\mathrm{F}_{1 \mathrm{~s}}$} & $\mathrm{O}_{1 \mathrm{~s}}$ & $\mathrm{Si}_{2 \mathrm{p}}$ & $\mathrm{Ca}_{2 \mathrm{p}}$ \\
\hline Untreated & 56.6 & - & 29.0 & 11.4 & 3.0 \\
Resin treated & 47.5 & 44.7 & 6.8 & 0.8 & 0.2 \\
Washed/dried & 52.6 & 25.7 & 15.7 & 5.0 & 1.0 \\
Heat-treated & & & & & \\
$50^{\circ} \mathrm{C} / 3 \mathrm{~min}$ & 49.5 & 31.2 & 13.6 & 4.9 & 0.8 \\
$80^{\circ} \mathrm{C} / 3 \mathrm{~min}$ & 48.4 & 37.9 & 10.6 & 2.7 & 0.4 \\
$120^{\circ} \mathrm{C} / 3 \mathrm{~min}$ & 46.7 & 34.4 & 13.4 & 4.4 & 1.1 \\
\hline
\end{tabular}

repellency of the fabric is much more greater comparing with that of the water repellency.

\subsection{ESCA analysis}

It is expected that change of the surface behavior during washing and following heat processing of the fluorocarbon resin treated fiber are apparently related to the surface chemical composition. So, ESCA analysis was carried out, and determined the relative intensity of the $\mathrm{C}_{1 \mathrm{~s}}$, $\mathrm{O}_{1 \mathrm{~s}}, \mathrm{~F}_{1 \mathrm{~s}}, \mathrm{Si}_{2 \mathrm{p}}$ and $\mathrm{Ca}_{2 \mathrm{p}}$.

Tables 4 and 5 show the surface relative intensities during the process. $\mathrm{Si}_{2 \mathrm{p}}$ and $\mathrm{Ca}_{2 \mathrm{p}}$ correspond to the original component of the glass fiber. As a matter of course, the parameters decreased by the resin treatment. Nevertheless the $\mathrm{Si}_{2 \mathrm{p}}$ intensity of the fabric increased by the washing. It is clear that the washing of the fabric caused a removal of the resin.

The $F_{1 s}$ intensity increased considerably by the resin treatment and decreased by the following washing, and then gradually increased with an elevation of the temperature of the heat treatment. On the other hand, the $\mathrm{O}_{1 \mathrm{~s}}$ intensity decreased by the resin treatment and increased by the washing. Furthermore, it decreased by the heat treatment.

Relationship between water repellency and ESCA measurement coincided with that of the previous paper on the cotton and polyester fabrics treated with fluorocarbon resin [4]. So, we supposed that an increase of the $\mathrm{O}_{1 \mathrm{~s}}$ intensity of the treated fabric by washing is attributed to the bound or clustered water on the fabric surface, especially on the resin surface. On the other hand, an increase of the $F_{1 s}$ intensity and a decrease of the $\mathrm{O}_{1 \mathrm{~s}}$ intensity are result of a release of the water by subsequent heat treatment.

From the above results, it is clear that change of the water and oil repellencies of the resin treated glass fabric by the washing and subsequent heat treatment takes place on the resin surface of the treated glass fiber regardless of the substrate chemical composition. It seems that perfluoroalkyl group of the fluorocarbon resin is difficult to rotate into glass fiber by the washing. With regard to the change of the water repellency of the glass fabric treated with fluorocarbon resin, we concluded that water molecules were taken on the resin surface by washing and release of the water by subsequent heat treatment. As the result, water repellency was recovered.

\section{Conclusion}

Glass fabric was treated with two kinds of commercial fluorocarbon resins, Asahi Guard AG-7000 
and AG-925 by means of the pad / dry / cure processing. Although water and oil repellencies increased considerably by the treatment, they decreased by the washing and recovered by subsequent heat treatment, especially over $80^{\circ} \mathrm{C}$. The behavior was almost the same with those of the treatment in a previous paper for polyester and cotton fabrics. Furthermore, as evident from the surface chemical composition by the ESCA analysis, the $F_{1 s}$ intensity increased considerably by the resin treatment, and decreased by the washing. The intensity increased again by subsequent heat treatment. On the other hand, the $\mathrm{O}_{1 \mathrm{~s}}$ intensity increased by the washing and decreased by the heat treatment. The behavior coincided well with the water and oil repellencies during the washing and subsequent heat treatment. Considering a change of the water repellency of the glass fabric treated with fluorocarbon resin, we concluded that the water molecules trapped on the resin surface by the washing and release of the water by subsequent heat treatment play an important role for the water repellency.

\section{References}

1. H. Ono, Dyeing Industry, 30, 460 (1982)

2. T. Wakida, T. Goto, H. Lee, T. Sato, M. Lee, and J. Chen, Sen 'i Gakkaishi, 50, 533 (1994).

3. F. Ide, 'Surface Modification of High Polymer', Kindai Kenkyusha, p.162 (1987).

4. T. Wakida, H. Lee, Y. Sato, H. Kawmura, M. Ueda, H. Mizushima, and S. Takekoshi, J. Soc. Dyers Colour, 109, 292 (1993).

5. Y. Sato, T. Wakida, S. Tokino. S. Niu, and M. Ueda, Textile Res. J ., 64, 316 (1994).

6. S. Arunyadej, R. Mitchell, J. Walton, and C. M. Carr, J . Textile Inst., 89, Part 1, No. 4, 696 (1998).

7. Y. Ikada, 'Fundamental and Application of Polymer Surface', Kagaku Donin, P. A69 (1986).

8. Y. Ikada, T. Matsunaga, and M. Suzuki, J. Chem. Soc. Jpn, 6, 1079 (1985).

9. T. Wakida, T. Mori, M. Saito, and C. Doi, Jpn. Res. Assn. Text. End-Uses, 42, 113 (2001).

10. AATCC Test Method 118-1992, AATCC Technical Manual 196 (1994). 